\title{
Erratum to: MRI of the wrist in juvenile idiopathic arthritis: proposal of a paediatric synovitis score by a consensus of an international working group. Results of a multicentre reliability study
}

\author{
Maria Beatrice Damasio • Clara Malattia • \\ Laura Tanturri de Horatio • Chiara Mattiuz • \\ Angela Pistorio - Claudia Bracaglia - Domenico Barbuti • \\ Peter Boavida • Karen Lambot Juhan • \\ Lil Sophie Mueller Ording • Karen Rosendahl • \\ Alberto Martini • GianMichele Magnano • Paolo Tomà \\ Published online: 20 October 2012 \\ (C) Springer-Verlag Berlin Heidelberg 2012
}

\section{Erratum to: Pediatr Radiol (2012) 42:1047-1055}

DOI 10.1007/s00247-012-2392-4

The original version of the article, unfortunately, contained the incorrect affiliation for Karen Rosendahl.

The correct affiliations are:

1. Institute of Surgical Sciences, University of Bergen, 5021

Bergen, Norway

2. Department of Radiology, Haukeland University Hospital, Jonas Liesvei 65, 5021 Bergen, Norway

The online version of the original article can be found at http://dx.doi.org/ $10.1007 / \mathrm{s} 00247-012-2392-4$.

M. B. Damasio $(\square) \cdot$ C. Mattiuz $\cdot$ G. Magnano

Department of Radiology, Ospedale Pediatrico Gaslini,

Genova, Italy

e-mail: beatrice.damasio@libero.it

C. Malattia $\cdot$ A. Martini

Department of Paediatrics, University of Genova,

Genova, Italy

L. Tanturri de Horatio $\cdot$ D. Barbuti $\cdot$ P. Tomà

Department of Radiology, Ospedale Pediatrico Bambino Gesu,

Rome, Italy

\section{A. Pistorio}

Department of Epidemiology and Biostatistics,

Ospedale pediatrico Gaslini,

Genova, Italy

C. Bracaglia

Department of Rheumatology,

Ospedale Pediatrico Bambino Gesù,

Rome, Italy
P. Boavida $\cdot$ L. S. M. Ording

Department of Radiology,

Great Ormond Street Hospital for Children,

London, UK

K. L. Juhan

Department of Radiology, Hopital Necker Enfants Malades, Paris, France

K. Rosendahl

Institute of Surgical Sciences, University of Bergen, 5021 Bergen, Norway

K. Rosendahl

Department of Radiology, Haukeland University Hospital, Jonas Liesvei 65 ,

5021 Bergen, Norway 